University of Nebraska - Lincoln

DigitalCommons@University of Nebraska - Lincoln

Marketing Department Faculty Publications

Marketing Department (CBA)

2008

Causes and consequences of grudge-holding in service relationships

Matthew P. Bunker

University of Northern lowa, matthew.bunker@uni.edu

Dwayne Ball

University of Nebraska-Lincoln, dball1@unl.edu

Follow this and additional works at: https://digitalcommons.unl.edu/marketingfacpub

Part of the Marketing Commons

Bunker, Matthew P. and Ball, Dwayne, "Causes and consequences of grudge-holding in service relationships" (2008). Marketing Department Faculty Publications. 14.

https://digitalcommons.unl.edu/marketingfacpub/14

This Article is brought to you for free and open access by the Marketing Department (CBA) at DigitalCommons@University of Nebraska - Lincoln. It has been accepted for inclusion in Marketing Department Faculty Publications by an authorized administrator of DigitalCommons@University of Nebraska - Lincoln. 


\title{
Causes and consequences of grudge-holding in service relationships
}

\author{
Matthew P. Bunker \\ College of Business Administration, University of Northern lowa, Cedar Falls, lowa, USA \\ Dwayne Ball \\ University of Nebraska-Lincoln, Lincoln, Nebraska, USA \\ Corresponding author - M.P. Bunker, matthew.bunker@uni.edu
}

\begin{abstract}
Purpose - The purpose of this paper is to place grudge-holding as a theoretical construct, measure it, and empirically place it in a nomological net and, additionally to discuss the consequences of grudge-holding in this research.

Design/methodology/approach - A $2 \times 2$ scenario-based experiment was performed using 320 subjects, approximately 80 people per condition. The size of the exit barrier (high/low) and the effectiveness of the service recovery (good/poor) were varied between each scenario to determine changes in grudge-holding.

Findings - Some consequences of grudge-holding are retaliation desire and communication avoidance. Although trust was tested in this research, and is still an important relationship variable, the results show that loss of trust cannot explain these outcomes in the presence of grudge-holding.

Research limitations/implications - The results are limited by the fact that they are based on scenarios rather than real events. As such, they should be interpreted with some caution, and confirmed by later studies using cross-sectional or natural experimental data.

Practical implications - A grudge-holding item should be included in routine customer satisfaction surveys, especially since grudgeholders are less likely to initiate communication. If grudge-holding is suspected, this paper suggests steps that managers can take to defuse grudges.

Originality/value - The results of this research confirm that grudge-holding is an important construct of service relationships. Understanding grudge-holding is important because it predicts the desire for retaliation and the desire to avoid communication, both of which can increase expenses for the firm, and eventually lead to a mass exit of customers.
\end{abstract}

Keywords: trust, service failures

An executive summary can be found at the end of this article.

Grudge-holding has been defined in a marketing context as "extreme exit," or the tendency to leave a customer relationship and never return (Hunt et al., 1988; Huefner and Hunt, 1992). We define it more precisely as a psychological process: maintaining a victim role and perpetuating negative emotions associated with rehearsing some hurtful offense (adapted from vanOyen Witvliet et al., 2001). Previous marketing literature has discussed the possible importance of grudge-holding by customers, but has not placed it properly in theory through empirical research.

Grudge-holding seems more likely to occur in service relationships than in any other type of customer relationship (such as brand relationships or product relationships). As Hunt et al. (1988) point out with reference to their results, "It was the treatment the customers received that seemed to have had a serious impact on how upset the person got." Serious grudge-holding, while it can theoretically occur in a brand relationship or a product relationship, is likely to require the repeated customer contacts characteristic of a service failure or the servicing of a product failure.

Aron (2001), for example, suggests that while grudgeholding, as a psychological process, may be linked to famil- iar marketing behaviors, such as exit from the relationship, lack of commitment, complaining, and negative word-ofmouth, grudge-holding may also be linked to "false loyalty" (a kind of avoidance behavior), and vengeance or retaliation. There are other logical causes of these consequences (particularly exit, loss of commitment, and complaining) - the service failure itself and consequent loss of trust. The idea that retaliation and avoidance behavior might be more direct consequences of grudge-holding, however, is intriguing. If this were to be confirmed empirically, then grudge-holding would have to be included as an important cause of important relationship outcomes.

The contribution of this study is to do so. We show that the well-established construct of trust does, as expected from previous literature, explain the most critical marketing outcome, customer commitment, even in the presence of grudge-holding. In the case of commitment, grudge-holding adds little explanatory power when the construct of trust is present. However, trust cannot explain a desire for retaliation or avoidance of the service provider - grudge-holding does. We show that even when consumers have the option of easily exiting a relationship with the service provider, know- 
ing that one can exit does not significantly reduce the effects of grudge-holding on retaliation desire and avoidance.

In terms of marketing theory, this:

- extends the definition of grudge-holding as "extreme exit" to a more psychological process; and

- calls for grudge-holding to be placed as an important construct in the theory of customer relationships.

\section{Theory and hypothesis development for grudge- holding: Reasons, antecedents, and consequences}

\section{Why do people hold grudges?}

Grudges are held over real or imagined wrongs by a service provider. Why are they held, especially when an outside observer might argue that the emotional energy invested in rehearsing the wrong might be better invested elsewhere? Why do people rehearse the wrongs done to them in a service relationship when there is often no positive solution for them? One answer is that holding a grudge towards a perpetrator of a wrongdoing provides the victim a moral high ground by virtue of having been wronged (Exline and Baumeister, 2000). As they point out, occupying the moral high ground restores a sense of power over one's life that had been lost through victimization ("If I cannot get satisfaction from the provider, at least I have the satisfaction of knowing that I am morally superior"). Some people can accept a loss of certain kinds of power (the power, for example, to determine the outcome of service transactions) with little reaction, but others feel the loss of power more acutely and require some means of regaining control, even if only in a psychological sense (Van Raaij and Pruyn, 1998).

\section{What are the antecedents of grudge-holding?}

Grudges in the marketplace can form for several different reasons, such as poor product quality, poor repair quality, and poor service (Hunt et al., 1988). Although some people may hold grudges due to a core product failure, Hunt $e t$ al. (1988) found that a majority of consumers hold grudges because of the way they were treated by marketing personnel. This finding underscores the importance of recognizing and effectively working with the interpersonal interaction that occurs between the service provider and the consumer (Iacobucci and Ostrom, 1996). But, grudges can be held regardless of the interpersonal interaction between service representative and customer. For example, airline penalties resulted in "resigned" bitterness, and one customer reportedly expressed disappointment with the penalty up to a year after the penalty occurred (Fram and Callahan, 2001). Thus, we will take poor service failure recovery, whether a result of interpersonal interaction or not, as the main cause of grudge-holding.

\section{Service failure and good/poor recovery}

As Bitner et al. (1990, p. 81) suggest, "offering sincere apologies, compensatory actions, and explanations can dissipate anger and dissatisfaction." A positive service recovery should lessen a consumer's grudge towards the offending service provider (Andreassen, 2001). Presumably, the lack of apologies, compensation, and explanation allow anger to remain. So it appears that customers do not necessarily hold grudges due to service failure, but it is the recovery effort of the firm that has a greater effect on grudges, since the initial victimization by the service failure is compounded by a lack of concern by the service provider for the customer's well-being:

H1. Grudge-holding will vary with the quality of service failure recovery.

\section{Exit barriers}

Another cause of holding a grudge is lack of ability to exit from the service. One might argue that exit is such a powerful form of regaining control that it should reduce the psychological need for holding a grudge. Conversely, the lack of ability to exit might exacerbate the need to hold a grudge to compensate for the wrong. For example, Wright and Larsen (1997) found that some BYU fans dissatisfied with the Alliance Bowl system (from which no exit was possible for a BYU fan) were motivated to hold grudges against the bowl system, especially those who believed that their complaints against the bowl system would be fruitless. However, the alternative argument is that people will hold a grudge against a service provider who has victimized them, even if they exit the relationship. Hunt et al. (1988) found cases of grudges being held 20 years after the termination of a marketing relationship. We will phrase the hypothesis below in the positive, but recognize the strong possibility that it may not hold true:

H2. Higher exit barriers will be associated with greater grudge-holding than lower exit barriers in the presence of poorly-recovered service failures.

\section{What are the relationship consequences of holding a grudge?}

Aron (2001), as pointed out above, mentions possible outcomes of grudge-holding as loss of commitment, exit, negative word-of-mouth, avoidance, and vengeance. We will discuss here commitment, avoidance, and vengeance.

Commitment, the most important outcome variable for marketers, "is the intention to behave in a manner supportive of relationship longevity" (Fournier, 1998, p. 365). Constructs such as trust, satisfaction, and perceived value have been repeatedly shown to predict customer loyalty and commitment (for examples, see Morgan and Hunt, 1994; Agustin and Singh, 2005). To date, no one has shown that grudgeholding (in the presence of these other predictors) has explanatory power:

\section{H3. Commitment will be negatively related to grudge-holding.}

Avoidance in a service context generally means avoidance of communication with the service provider, either one-way or two-way. Consumers can refuse to initiate contact with the service provider, can refuse to complain, fail to open mail or e-mail, or can find ways to be unavailable for communications from the service provider, even though a service relationship may still exist. Communication avoidance is a serious relationship problem. Halstead et al. (1996) noted that "nothing is worse than failing to detect a problem or failing to obtain information from a dissatisfied customer". Stephens and Gwinner (1998) point out that when customers refuse to communicate, the company loses the opportunity to remedy a problem, is deprived of valuable feedback about its products and services, and loses the opportunity to retain the customer and others with similar complaints.

There are a number of reasons that a customer might avoid communication. Andreasen and Manning (1990), for 
example, mention a feeling of vulnerability. Stephens and Gwinner (1998) mention personality factors, and attitude against complaining, cost of complaining, bad experiences from previous communications, and so forth, but do not mention grudge-holding. However, it seems to us that someone nursing a grudge - a rehearsal of victimization by the firm - might well find several reasons to avoid communication with the firm.

First, communication may result in new information that makes the consumer's culpability in the incident of victimization manifest, thus the consumer may stand to lose the moral high ground by communicating. In addition, a grudge-holder generally will hold ill-will towards, and a negative image of, the service provider. Communication potentially allows the service provider to correct this image, and thus, again, the customer loses the moral high ground. The grudge-holding consumer may also believe that time invested in communication with the service provider is a waste, based on past experience. Finally, communication may result in yet another incident of wrong against the customer. Conflict laden communication may leave the consumer with subsequent pain, feelings of vulnerability, and sense of having been taken advantage of by the company. So, we believe there are strong reasons for grudge-holding to be a cause of reduced communication between the customer and service provider:

H4. Communication avoidance will be positively associated with grudge-holding.

Vengeance, or retaliation by the customer against the service provider, may take many forms. For example, a customer angered at a public utility may write a letter to the editor derogating the company. Some consumers may contemplate physical violence or vandalism against the firm or its representatives (Huefner and Hunt, 2000), or they may just use negative word-of-mouth as a retaliation strategy (Fram and McCarthy, 1999). Bougie et al. (2003), in a content analysis of open-coded questions exploring feelings, thoughts, action tendencies, actions, and "emotivational goals" after a negative service incident, found such things as desires for revenge, tendencies toward aggressive actions, and desires to harm the firm or someone at the firm. Most desires for retaliation, of course, are not implemented, but some are. The mere desire for retaliation bodes ill for a relationship. Some fraction of retaliation desires will result in actual acts of retaliation, and these can be costly to the firm and a drag on the bottom line. It would be preferable to develop hypotheses about retaliation. However, because measuring actual retaliation is fraught with serious problems, we will only concern ourselves with the desire for retaliation. Therefore, we will concern ourselves with the desire for retaliation. We suggest that grudge-holding, being pervasive and long-term ill-will towards a service provider after one or more negative incidents (a "commitment to remain angry" according to van Oyen Witvliet et al., 2001), may be strongly linked to desires for retaliation:

H5. Desire for retaliation will be positively related to grudge-holding.

\section{The effect of trust: A competing explanation.}

Trust is generally conceded to be a central construct in relationships. Along with satisfaction and value, trust has been found to be a strong driver of commitment and loyalty (Agustin and Singh, 2005; Doney and Cannon, 1997; Ganesan, 1994; Garbarino and Johnson, 1999; Morgan and Hunt,
1994; Oliver, 1999; Sirdeshmukh et al., 2002). Trust has been conceptualized in a number of forms, such as Ganesan's (1994) distinction between credibility trust (confidence that the service will be delivered satisfactorily) and benevolence trust (confidence that the service provider will not take advantage of the relationship).

Trust is a potential competing explanation for the effects described in $H 3, H 4$, and $H 5$. It is reasonable, perhaps, to think that loss of trust after a poorly-recovered service failure may account for loss of commitment, increased communication avoidance, and increased retaliation desire. Benevolence trust seems to compete with grudge-holding, even though we expect the same incident that drives lowered trust to drive increased grudge-holding to a large extent. If one believes that the service provider is opportunistic (a likely outcome of victimization), then certainly, commitment would drop substantially. Furthermore, one might also wish to avoid communication with an opportunistic service provider (to avoid additional opportunism), and one might desire to retaliate against someone who had taken advantage.

Could these effects exist in the absence of grudge-holding, however? Certainly, in the case of commitment, it can drop even when grudge-holding is not strongly evident. One might lose benevolence trust of a service provider - simply due to a serious service failure, even if well-recovered without developing a grudge, and yet become very uncommitted to the relationship. Benevolence trust could be low and therefore commitment could be low; the additional effect of a strong grudge might not lower commitment much further. We therefore expect benevolence trust to provide a much stronger explanation for the level of commitment:

H6. Benevolence trust will be more strongly related to commitment than will grudge-holding.

The same arguments might also be applied to retaliation desire and communication avoidance. Belief that the service provider is opportunistic could lead to lack of a desire to communicate and a strengthened desire to retaliate. In fact, we expect to find bivariate relationships between benevolence trust and the constructs communication avoidance and retaliation desire. However, there are good counter-arguments that grudge-holding will explain the variability in communication avoidance and retaliation desire much better than loss of benevolence trust. Merely believing that a service provider is opportunistic may be an insufficient reason to invest emotional energy in desires for retaliation. On the other hand, holding a grudge-rehearsing victimization by the service provider - gives a reason: the restoration of one's self-esteem, status, or sense of justice (Aquino et al., 2001) through retaliation or retaliation fantasies:

H7. In the presence of grudge-holding, trust will not explain the variability in retaliation desire.

There are also arguments that communication avoidance may be more a function of grudge-holding than loss of benevolence trust. Consider the case in which one believes the service provider is opportunistic, but one holds no grudge. What, then, would be the reason to avoid communication? Perhaps one would feel that communication could lead to an incident in which the service provider would take advantage of the customer. However, most consumers are probably confident that they can "handle" such behavior by a service provider during a communication. But, if a customer holds a grudge, communication does involve the risk, as mentioned 
above, of losing the moral high ground, which is the reason for the grudge-holding in the first place. Therefore, we expect that communication avoidance will be better-explained by grudge-holding than loss of benevolence trust:

H8. In the presence of grudge-holding, trust will not explain the variability in communication avoidance.

\section{Methodology}

The methodology for this study was an experiment using scenarios. A pre-test of the experiment was performed to establish measurement characteristics and to test manipulations.

\section{Experimental design}

The experiment was performed by presenting one of four randomly chosen scenarios to each of 320 persons, approximately 80 per scenario. The subject was asked to imagine that he or she had just moved to a new town and signed up for local telephone service with a local service provider. In two of the scenarios telephone service was a competitive market (the low exit barrier conditions) in which the consumer could choose another local provider or a cellular phone provider. In the other two scenarios (the high exit barrier conditions), there was no cellular phone provider and the local telephone company was the only alternative source of telephone service. A set of questions were then filled out by each respondent to gauge an understanding of the constructs measured in this study, before a service failure even occurs.

Afterwards, the scenario continued with a severe and long-term failure in telephone service. Then the scenario described the company's recovery from this failure in one of two ways. One of the scenarios in each exit barrier condition described the telephone company executing an excellent recovery from the service failure. The other scenario in each exit barrier condition described a very poor recovery from the service failure. The scenarios are provided in the appendix. The service recovery scenarios for this research included the four attributes of Smith et al. (1999): compensation, response speed, apology, and recovery initiation. The two service recovery conditions (good, poor) and the two exit barriers (high, low) were established in order to test $H 1$ and $H 2$. Finally, the five constructs of trust, grudge, retaliation desire, avoidance of communication and commitment were measured, in order to test the remaining hypotheses.

A pre-test manipulation was performed that measured the quality of the recovery and verified that the service recovery manipulation was strong, and measured the subjects' perception of the difficulty of switching to confirm that the exit barrier manipulation was strong.

\section{Sample}

Adults recruited by four community groups (a women's group, a group of Boy Scout parents, and two parochial school groups) participated as a fundraiser. Six additional subjects were recruited individually. As one can see from Table I, the respondents were quite diverse in terms of sex, income, age, and occupation. While not a perfect probability sample of the USA, and therefore unsuitable for projecting mean levels of the constructs to the population, a diverse sample of this type should nonetheless serve to find relationships between constructs, where they exist in the population.
Table I. Sample demographics

\begin{tabular}{|c|c|c|}
\hline & $N$ & $\%$ \\
\hline \multicolumn{3}{|l|}{ Sex } \\
\hline Male & 118 & 36.9 \\
\hline Female & 197 & 61.6 \\
\hline Missing & 5 & 1.6 \\
\hline \multicolumn{3}{|l|}{ Income } \\
\hline Less than $\$ 20,000$ & 55 & 17.2 \\
\hline$\$ 20,000-\$ 35,000$ & 55 & 17.2 \\
\hline$\$ 35,001-\$ 50,000$ & 106 & 33.1 \\
\hline$\$ 50,001-\$ 65,000$ & 28 & 8.8 \\
\hline$\$ 65,001-\$ 100,000$ & 46 & 14.4 \\
\hline More than $\$ 100,000$ & 8 & 2.5 \\
\hline Missing & 22 & 6.9 \\
\hline \multicolumn{3}{|l|}{ Age } \\
\hline $19-25$ & 30 & 9.4 \\
\hline $26-35$ & 74 & 23.1 \\
\hline $36-45$ & 110 & 34.4 \\
\hline $46-60$ & 54 & 16.9 \\
\hline $60-75$ & 26 & 8.1 \\
\hline 76 or older & 21 & 6.6 \\
\hline Missing & 5 & 1.6 \\
\hline \multicolumn{3}{|l|}{ Occupation } \\
\hline Student & 8 & 2.5 \\
\hline Retired & 16 & 5.0 \\
\hline Homemaker & 28 & 8.8 \\
\hline Skilled, semi-skilled, farming & 49 & 15.3 \\
\hline Clerical and sales & 41 & 12.8 \\
\hline Professional/managerial & 114 & 35.6 \\
\hline Missing & 64 & 20.0 \\
\hline Total & 320 & 100.0 \\
\hline
\end{tabular}

Out of 326 questionnaires, 320 were useable. The four scenarios were randomized across the subjects in each group.

\section{Measurements}

The five multi-item Likert scales were developed and refined through pre-testing, item analysis, multiple method validation, and assessment of convergent and discriminant validity. The final items for trust, grudge-holding, retaliation desire, communication avoidance and commitment are shown in Table II.

Scale reliabilities and convergent validities are shown in Table III. Reliability was assessed by Cronbach's alpha, and all scales showed values above 0.8. Convergent validity was assessed by using a semantic differential measure for each construct in addition to the multi-item Likert scale. The correlations between the two different types of measure for each construct constitute a rough assessment of convergent validity (a more rigorous assessment of convergent validity would not use two pen-and-paper methods, but an extremely different form of measurement method was not possible in this research). As can be seen from Table III, the correlations between the two types of measures for each scale are high, and almost always higher than the correlations between measures of different constructs. Means, standard deviations, and correlations among the constructs (when measured as composite scores) are in Table IV. 
Table II. Construct items

\section{Trust}

This local telephone company has my best interests at heart

I feel that this is a company that is likely to take advantage of its customers (reversed)

Overall, this firm is trustworthy

I would expect representatives of this phone company to be completely honest with me about any future problems with my service This company is the type to be straightforward with its customers

I would expect representatives of the company to hide the truth from me about problems in the future (reversed)

I think that this telephone company typically would not take advantage of its customers

\section{Commitment}

If asked about this telephone company, I would give it a good rating

Whether or not an alternative is available, I still wouldn't want to change telephone companies

Even if close friends recommended dropping the service offered by this local telephone company, I would not change my preference for this company

I would like to maintain a relationship with this firm for a very long time

If given the chance, I would drop this telephone service (reversed)

If I had the chance to switch, I would still remain faithful to this company

If somebody talked badly about this company I would stand up for it

\section{Grudge}

A reasonable person would find it hard to forgive this company

I would harbor a grudge against this telephone company

If this firm ever came to mind, I would probably remember their treatment of me with some bitterness

It would be difficult for me to forget the problem I had with this company

I would think poorly of this telephone company for a long time It would be difficult to forgive this company for treating me this way

\section{Retaliation desire}

If I thought I could get away with it, l'd find some way to pay this company back for what they did to me

I would like to see this telephone company suffer because of the trouble it caused me

I could think of ways to get back at this company

It would frustrate me to think that I could not get back at this company even if I wanted

I really would not have any desire to retaliate (reversed)

Entertaining thoughts of retaliation towards this telephone company seems like a silly idea to me (reversed)

\section{Communication avoidance}

It would not be worth my time to call this company about future service problems

Pursuing future service problems would only bring more grief between this company and me

I would put off complaining to the company if this problem happened again

I would have no problem contacting this company if the phone would not work again (reversed)

If I encountered another problem with this company, I would procrastinate calling them until it was absolutely necessary

If I started missing conversations again in the future, I would not call this telephone company for help, as that would only frustrate me further
Discriminant validity of the constructs was established using Anderson and Gerbing's (1988) confirmatory factor analysis (CFA) method. EQS software was used to test a measurement model in which each item presumed to load on each construct, and all covariances between constructs were allowed to vary. Then, a pair of CFA analyses was performed for each pair of constructs. First, the covariance between a pair of constructs was fixed to 1 , all other covariances were constrained to be equal, and the model was solved, and that covariance was allowed to relax and the model was solved. The Chi-square difference in fit between the two models is a test (with $1 \mathrm{df}$ ) of discriminant validity between the pair of constructs. All Chi-square difference tests were statistically significant at 0.001 , indicating that the six constructs were discriminable.

\section{Data analysis}

The first two hypotheses were tested by ANOVA. A twoway ANOVA was performed with grudge-holding as the dependent variable and recovery quality and exit barrier as the independent variables (a $2 \times 2$ between-subjects design). The main effect of recovery quality is the test of $H 1$, and the comparison between the high and low exit barrier conditions for the poor recovery condition is the test of $\mathrm{H} 2$. $\mathrm{H} 3, \mathrm{H} 4, \mathrm{H} 5$, and $\mathrm{H} 6$ were tested using a structural equation model (see Figure 1) using EQS software. Subsequently, to test $H 7$ and $H 8$, two paths were added, one at a time, to the model in Figure 1: paths from trust to retaliation desire and from trust to communication avoidance. This second procedure was done to confirm that trust does not directly affect those constructs in the presence of grudge-holding. If this were not true, then the construct of grudge-holding would not be necessary to theory.

\section{Results}

\section{Exit barriers and service recovery}

Table V compares the mean differences for grudge-holding between high and low exit barriers and for grudge-holding between high and low service recovery. There is a main effects difference for grudge-holding in the recovery quality condition $(F=90.377, p<0.001)$ thus supporting $H 1$, grudgeholding is more likely to occur with poor service recovery efforts, whereas a good recovery can diffuse the tendency to hold a grudge.

Table $\mathrm{V}$ also shows that there was no significant difference between the means for grudge-holding in the high and low exit barrier conditions $(F=0.280, p=0.597)$, thus failing to support $\mathrm{H} 2$.

The model described in Figure 1 was tested using EQS, and the model fit well $\left(\chi^{2}=1008.8, \mathrm{df}=456, \mathrm{CFI}=0.974, \mathrm{RM}-\right.$ SEA $=0.062)$. We also added a path from trust to retaliation desire which resulted in no significant improvement in the model $\left(x^{2}=1008.0, d f=455\right)$, and the path coefficient was not significant $(t=1.35, \beta=0.146)$. Next we added a path from trust to communication avoidance and there was no significant improvement between that model and the original model described in Figure $1\left(x^{2}=1008.0, d f=455\right)$, and the path coefficient was not significant $(t=1.5, \beta=-0.192)$. The next test involved creating a full model in which paths were tested between trust and the three dependent variables (commitment, retaliation desire, and communication avoidance). 


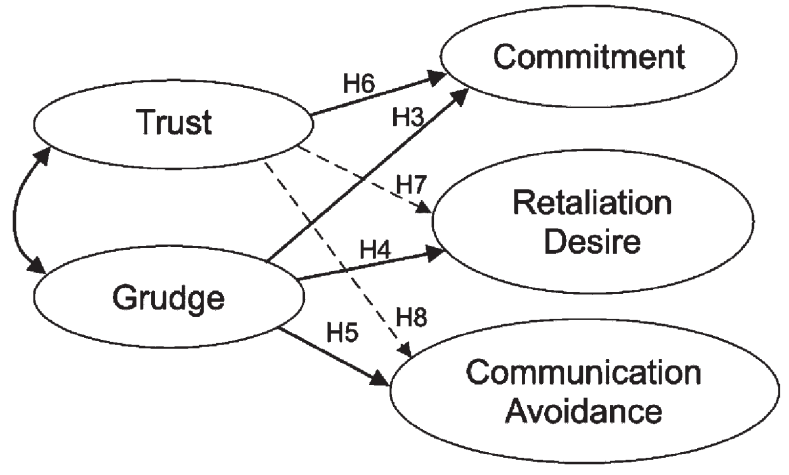

Figure I. Structural equation model

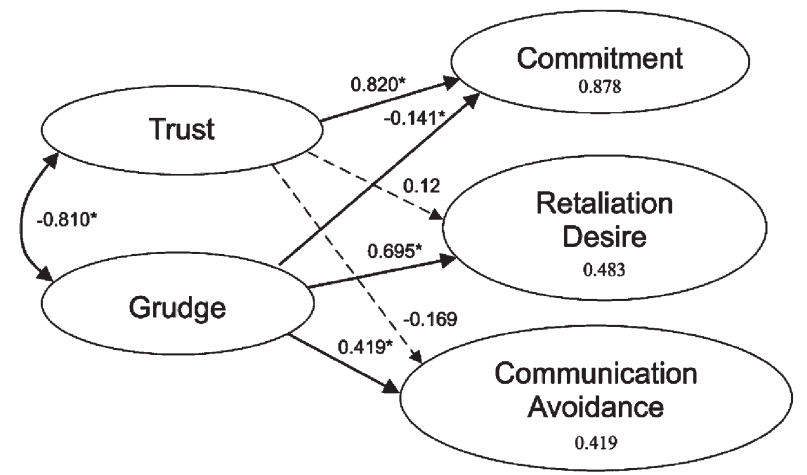

Figure 2. Results of structural equation model

Table III. Reliability and validity of constructs

\begin{tabular}{|c|c|c|c|c|c|}
\hline Scale & Cronbach's alpha & Validity * & $\begin{array}{l}\text { Highest other } \\
\text { correlation } * *\end{array}$ & $\begin{array}{l}\text { Number of higher } \\
\text { correlations } * * *\end{array}$ & $\begin{array}{c}\text { Percentage of } \\
\text { correlations lower }\end{array}$ \\
\hline Trust & 0.881 & 0.77 & 0.82 & I & 94 \\
\hline Retaliation desire & 0.886 & 0.72 & 0.63 & 0 & 100 \\
\hline Communication avoidance & 0.826 & 0.63 & 0.36 & 0 & 100 \\
\hline Commitment & 0.929 & 0.84 & 0.79 & 0 & 100 \\
\hline
\end{tabular}

Table IV. Means/standard deviations and correlations between constructs

\begin{tabular}{|c|c|c|c|c|c|c|c|c|c|c|}
\hline & \multicolumn{2}{|c|}{ Trust } & \multicolumn{2}{|c|}{ Grudge } & \multicolumn{2}{|c|}{ Retaliation desire } & \multicolumn{2}{|c|}{$\begin{array}{c}\text { Commmunication } \\
\text { avoidance }\end{array}$} & \multicolumn{2}{|c|}{ Commitment } \\
\hline & Mean & $\mathrm{SD}$ & Mean & SD & Mean & SD & Mean & SD & Mean & SD \\
\hline Grudge & $-0.708 *$ & & 4.18 & 1.30 & & & & & & \\
\hline Retaliation desire & $-0.467 *$ & & $0.617 *$ & & 2.67 & 1.17 & & & & \\
\hline Communication avoidance & $-0.419 *$ & & $0.416 *$ & & $0.390 *$ & & 2.71 & 1.08 & & \\
\hline
\end{tabular}

* Correlation is significant at the 0.01 level

Table V. Means of grudge-holding by recovery quality and exit barrier

\begin{tabular}{lllll}
\hline & \multicolumn{4}{c}{ Exit barrier } \\
& & Low & High & Total \\
\hline Recovery quality & Low & 4.85 & 4.80 & $4.82 *$ \\
& High & 3.64 & 3.56 & $3.60 *$ \\
Total & & 4.23 & 4.14 & \\
\hline
\end{tabular}

* Recovery quality means significantly different at $p<0.0005$; no other effects significant at $p<0.05$

This model also showed no significant improvement from the original model $\left(x^{2}=1008.9, \mathrm{df}=454\right)$, and these additional path coefficients were not significant (path coefficient between trust and retaliation desire is $t=1.5, \beta=-0.192$; path coefficient between trust and communication avoidance is $t=-0.169, \beta=-0.169$ ).

Figure 2 shows the results of testing the structural equation model described in Figure 1. The results show the strong impact of grudge on retaliation desire and communication avoidance, thus supporting $\mathrm{H} 4$ and $\mathrm{H} 5$.

Consistent with the literature, trust is still a very strong predictor of commitment $(\mathrm{H} 6)$, much more so than grudgeholding. In fact, the impact of grudge-holding on commitment is very small as shown in the path coefficient (H3). As noted earlier in the results, the added path models from trust to retaliation desire $(H 7)$ and from trust to communication avoidance $(H 8)$ were small and insignificant and did not significantly change the overall model fit. 
While we had no explicit hypotheses regarding the relationships between demographic characteristics and grudgeholding, retaliation desire, and communication avoidance, we did investigate differences between mean levels of those constructs. Men had higher means for grudge-holding, retaliation desire, and communication avoidance than women, as displayed in Table VI. There were no such differences attributable to income. In terms of age, younger people in the sample tended to hold grudges more strongly than older people, but showed no significant differences in retaliation desire or communication avoidance. These effects are interesting, but seem consistent with what one would expect.

The results of the hypothesis tests are summarized in Table VII.

\section{Discussion}

\section{Implications for theory}

We believe that the meaning of these results is to confirm empirically what earlier authors have suggested - grudgeholding needs a place in the theory of service relationships. This would not be placed as prominent as trust. Trust is still one of the large determinants of commitment, and grudgeholding is not, although it appears to enhance the effect of a loss of trust on commitment. Furthermore, our data can only confirm the likelihood of grudge-holding under

Table VI. Mean differences between men and women with grudgeholding, retaliation desire and communication avoidance

\begin{tabular}{lrrrr}
\hline Construct & Men mean & Women mean & $F$ & Sig. \\
\hline Grudge & 4.42 & 4.02 & 7.06 & 0.008 \\
Retaliation desire & 2.99 & 2.46 & 15.88 & $<0.001$ \\
Communication avoidance & 2.92 & 2.57 & 8.06 & 0.005 \\
\hline
\end{tabular}

Table VII. Summary of hypotheses and results

\begin{tabular}{ll}
\hline Hypotheses & Results \\
\hline $\begin{array}{l}\text { HI.Grudge-holding will vary with the quality of } \\
\text { service failure recovery }\end{array}$ & Supported \\
$\begin{array}{l}\text { H2. Higher exit barriers will be associated with } \\
\text { greater grudge-holding than lower exit } \\
\text { barriers in the presence of poorlyrecovered } \\
\text { service failures }\end{array}$ & Not supported \\
H3. Commitment will be negatively related to & \\
grudge-holding & Not supported \\
H4. Communication avoidance will be positively & \\
associated with grudge-holding & Supported \\
H5. Desire for retaliation will be positively & \\
related to grudge-holding & Supported \\
H6. Benevolence trust will be more strongly & \\
related to commitment than will grudgeholding & Supported \\
H7. In the presence of grudge-holding, trust will & \\
not explain the variability in retaliation desire & Supported \\
$\begin{array}{l}\text { H8. In the presence of grudge-holding, trust will } \\
\text { not explain the variability in communication } \\
\text { avoidance }\end{array}$ & \\
\hline
\end{tabular}

service failure followed by poor recovery. Without these conditions, grudge-holding seems unlikely. So, the place of grudge-holding in customer relationship theory is limited, but important.

It is important because grudge-holding predicts the desire for retaliation and the desire to avoid communication. Grudge-holding is a psychological process of ruminating over victimization by the service provider, and may well drive the customer away from the service provider and towards thoughts of vengeance. As previously discussed, these are potentially expensive outcomes for the service provider.

Previous definitions of grudge-holding as "extreme exit" (Hunt et al., 1988; Huefner and Hunt, 1992) are somewhat incomplete and lead to incomplete understanding of the effects of grudge-holding. We can complete and extend them by pointing out that grudge-holding is better conceived as a psychological process that can and does occur whether the customer can exit the relationship or not. Furthermore, the effects of grudge-holding are substantially the same whether or not the customer exits the relationship. He or she will still hold a grudge, and he or she will still desire retaliation and wish to avoid future communications with the service provider.

\section{Implications for management}

The fact that unhappy customers hold the same level of grudge whether they exit the relationship or not raises a strong possibility of a notable effect. For any service provider who has been in business long enough to have committed service failures and poor recoveries, there are former customers in his or her market area still nursing a grudge, still throwing away communications from the service provider, and still wishing that the service provider would fall down a hole. Those customers may be taking vengeance simply by negative word of mouth, or by some other means. In addition, for service providers that have some sort of monopoly in their service area, such customers may exist and may still be doing business with the service provider, which may put the service provider at risk of committing additional acts that will be interpreted as victimization, and possible consequent actual acts of retaliation. For example, one might wonder how many customers in suddenly-deregulated or de-monopolized industries leave a service provider due to the conditions that cause grudge-holding. There are, of course, other customers who have suffered the same service failures and bad recoveries, but have put the matter behind them and do not nurse a grudge.

Grudge-holding is certain to be a matter of individual differences. Faced with the same service failures, some customers will hold a deep grudge, and some will cope in other ways. Thus, a service provider, encountering customers who do not exit, and who do not hold grudges, and who are willing to continue communication, may be fooled into thinking that this is the response of most customers to service failure. But, it does seem clear that the consequences of having grudge-holding customers can be very negative, and that firms would benefit from knowing if more than a few customers hold a grudge over some past event, and from systematically preventing such events from occurring.

\section{Prevent service failures where possible}

To prevent grudge-holding, managers should avoid service failure in the first place. This means putting in place pol- 
icies, practices, and training that allow service personnel to recognize when mere dissatisfaction will become grudgeholding, with all the attendant negative consequences.

\section{Recover well from service failures}

When service failures do occur, managers should adopt Smith et al.'s (1999) four steps to good recovery from service failure: apology, compensation, response speed, and recovery initiation.

\section{Monitor grudge-holding in the customer population}

Routine customer satisfaction surveys should have a grudge-holding item or two, in order to detect the level of grudge-holding, particularly since, as our results show, grudge-holders are less likely to initiate communication. In addition, perusal of company-focused complaint websites and searches of weblogs may uncover a lot of grudgeholding (examples: http://www.untied.com , http://www. uSpeakOut.com, and http://www.complaints.com ). Finally, managers should monitor the level of apparent acts of retaliation and communication avoidance. Acts of retaliation can be vandalism, negative word-of-mouth, and passive-aggressive acts (such as paying a bill in pennies). Communication avoidance due to grudge-holding might be detected by the ratio of dissatisfied customers to complainers. If this ratio is higher than normal benchmarks for the company or industry, it would suggest that unhappy customers are avoiding communication in greater numbers than usual, indicating grudge-holding.

\section{Take action to defuse grudges}

The first step is to identify customers with grudges. Since it is unlikely that they will initiate communication to resolve the grudge, the company must take the initiative in opening communications. Perhaps customers likely to hold grudges can be identified by mining a customer database. For example, the company may have discovered that customers exposed to certain policies or receiving service in certain locations under certain conditions are likely to hold grudges. In this case, such customers can be approached individually and the problem corrected with sensitivity to their state of mind and appropriate apologies and compensation. Steps should be taken to avoid further service failures of the types that resulted in grudges.

If grudge-holding customers cannot be reliably identified in the customer database, then the service provider may be forced into a difficult position. If the amount of grudgeholding is very low, it may be prudent to merely put policies in place to avoid repeating the incidents that gave rise to the grudges, to avoid future grudge-holding customers. However, if the amount of grudge-holding is substantial, then the company may find itself with the necessity of initiating a public relations campaign to encourage still-angry customers to identify themselves and thereby receive apologies and compensation. To fail to do so would be to incur the possible consequences of large-scale grudge-holding: exodus of customers, retaliation, and communication avoidance on a large scale.

This model helps to explain the powerful effects of grudge-holding on retaliation desire and communication avoidance. Retaliation and communication avoidance are important constructs in relationship marketing because they are not always evident to a marketer. But if retaliation desire were to convert to actual retaliation, the effect on the marketer may be worse (such as vandalism or harassment) than just a lost customer.

\section{Limitations and future research}

Our results are limited by the fact that they are based on scenarios rather than real events. As such, they should be interpreted with some caution, and confirmed by later studies using cross-sectional or natural experimental data. However, the control provided by an experiment allows us to rule out at least some threats to validity that would be present in other forms of data. Also, as mentioned above, we varied only the quality of the service recovery and the size of the exit barrier as independent variables, in order to achieve variance in grudge-holding. There may certainly be other ways of creating conditions ripe for grudge-holding, such as sudden poorly-explained price increases or an offensive mass communication, but we suspect service failure followed by poor recovery is the one that occurs most often. Finally, the sample used, while demographically fairly diverse, is not a probability sample of USA consumers. We think it unlikely that the causes and consequences of grudge-holding are substantially different in the entire population; however, there may certainly be some USA subpopulations (the very wealthy or the very poor, for example), that respond with greater or lesser intensity than our results indicate.

Avenues of future research might explore events which defuse grudges, the actual costs of grudge-holding (through retaliation and communication avoidance), and the individual differences that predict grudge-holding. If persons with likely grudge-holding tendencies can be identified, there may be ways for a company to deal with them in advance that will ameliorate the costs of doing business with them if they begin to hold a grudge. Finally, research on the conversion of retaliation desire into actual retaliation would be valuable.

\section{References}

Agustin, C., JSingh, J. (2005), "Curvilinear effects of consumer loyalty determinants in relational exchanges," Journal of Marketing Research, Vol. 42, No. 1, pp. 96-115.

Anderson, J. C., Gerbing, D. W. (1988), "Structural equation modeling in practice: a review and recommended twostep approach," Psychological Bulletin, Vol. 103, No. 3, pp. 411-23.

Andreasen, A. R., Manning, J. (1990), “The dissatisfaction and complaining behavior of vulnerable consumers," Journal of Consumer Satisfaction, Dissatisfaction, and Complaining Behavior, Vol. 3 pp. 12-20.

Andreassen, T. W. (2001), "From disgust to delight: do customers hold a grudge?," Journal of Service Research, Vol. 4, August, pp. 39-49.

Aron, D. (2001), "Consumer grudgeholding: toward a conceptual model and research agenda," Journal of Consumer Satisfaction, Dissatisfaction, and Complaining Behavior, Vol. 14, pp. 108-19.

Aquino, K., Tripp, T. M., Bies, R. J. (2001), “How employees respond to personal offense: the effects of blame, attribution, victim status, and offender status on revenge and reconciliation in the workplace," Journal of Applied Psychology, Vol. 86, No. 1, pp. 52-9. 
Bitner, M. J., Booms, B. H., Tetreault, M. S. (1990), “The service encounter: diagnosing favorable and unfavorable incidents," Journal of Marketing, Vol. 54, January, pp. 71-84.

Bougie, R., Pieters, R., Zeelenberg, M. (2003), "Angry customers don't come back, they get back: the experience and behavioral implications of anger and dissatisfaction in services," Journal of the Academy of Marketing Science, Vol. 31, No. 4, pp. 377-93.

Doney, P. M., Cannon, J. P. (1997), “An examination of the nature of trust in buyer-seller relationships," Journal of Marketing, Vol. 61, April, pp. 35-51.

Exline, J. J., Baumeister, R. F. (2000), “Expressing forgiveness and repentance: benefits and barriers," in McCullough, M. E., Pargament, K. I., Thoresen, C. E. (eds.), Forgiveness: Theory, Research, and Practice, Guilford Press, New York, NY.

Fram, E. H., Callahan, A. (2001), "Do you know what the customer you penalized yesterday is doing today?," Journal of Services Marketing, A pilot analysis, Vol. 15, No. 6/7, pp. 496-509.

Fram, E. H., McCarthy, M. S. (1999), “The true price of penalties," Marketing Management, Vol. 8, No. 3, pp. 48-56.

Fournier, S. (1998), "Consumers and their brands: developing relationship theory in consumer research," Journal of Consumer Research, Vol. 24, March, pp. 343-73.

Ganesan, S. (1994), "Determinants of long-term orientation in buyer-seller relationships," Journal of Marketing, Vol. 58, April, pp. 1-19.

Garbarino, E., Johnson, M. S. (1999), "The different roles of satisfaction, trust, and commitment in customer relationships," Journal of Marketing, Vol. 63, April, pp. 70-87.

Halstead, D., Morash, E. A., Ozment, J. (1996), “Comparing objective service failures and subjective complaints: an investigation of domino and halo effects," Journal of Business Research, Vol. 36, pp. 107-15.

Huefner, J. C., Hunt, H. K. (1992), “Brand and store avoidance: the behavioral expression of dissatisfaction," Journal of Consumer Satisfaction, Dissatisfaction and Complaining Behavior, Vol. 5, pp. 228-32.

Huefner, J. C., Hunt, H. K. (2000), “Consumer retaliation as a response to dissatisfaction," Journal of Consumer Satisfaction, Dissatisfaction and Complaining Behavior, Vol. 13, pp. 61-82.

Hunt, H. K., Hunt, H. D., Hunt, T. C. (1988), “Consumer grudge holding," Journal of Consumer Satisfaction, Dissatisfaction and Complaining Behavior, Vol. 1, pp. 116-18.

Iacobucci, D., Ostrom, A. (1996), “Commercial and interpersonal relationships; using the structure of interpersonal relationships to understand individual-to-individual, individual-to-firm, and firm-to-firm relationships in commerce," International Journal of Research in Marketing, Vol. 13, pp. 53-72.

Morgan, R. M., Hunt, S. D. (1994), “The commitment-trust theory of relationship marketing," Journal of Marketing, Vol. 58, July, pp. 20-38.

Oliver, R. L. (1999), “Whence consumer loyalty?," Journal of Marketing, Vol. 63 (Special Issue), pp. 33-44,

Sirdeshmukh, D., Singh, J., Sabol, B. (2002), "Consumer trust, value, and loyalty in relational exchanges," Journal of Marketing, Vol. 66, No. 1, pp. 15-37.

Smith, A. K., Bolton, R., Wagner, J. (1999), “A model of customer satisfaction with service encounters involving failure and recovery," Journal of Marketing Research, Vol. 36, August, pp. 356-72.

Stephens, N., Gwinner, K. P. (1998), “Why don't some people complain? A cognitive-emotive process model of con- sumer complaint behavior," Journal of the Academy of Marketing Science., Vol. 26, No. 3, pp. 172-89.

Van Raaij, W. F., Pruyn, A. Th. H. (1998), “Customer control and evaluation of service validity and reliability," Psychology and Marketing, Vol. 15, pp. 811-32.

van Oyen Witvliet, C., Ludwig, T. E., Vander Laan, K. L. (2001), "Granting forgiveness or harboring grudges? Implications for emotion, physiology, and health," Psychological Science, Vol. 12, No. 2, pp. 117-23.

Wright, N. D., Larsen, V. (1997), "Complaining about the alliance: extending Kowalski's theory of complaining through a hermeneutical analysis of online complaining data," Journal of Consumer Satisfaction, Dissatisfaction and Complaining Behavior, Vol. 10, pp. 170-84.

\section{Appendix. Four experimental scenarios used for service failure research}

\section{Scenario 1: High exit barrier and poor service recovery}

You just moved into an area of the country where the only phone service available is provided through one local telephone company. Cellular phone service is not an option available for residents of this area. So, you are limited to a single provider of local telephone service. After finding a place to live, you gather information about this particular telephone provider. Based off of the information that you collected about this provider, you contact this local telephone company in order to set up your phone service.

After two months of receiving good service from your local telephone provider, you begin to notice that you cannot hear people talking on the phone, although they can hear you talk. This problem is frustrating and annoying; as it requires that you hang up and call the person back in order to complete your phone conversation. You call the telephone company and tell them the problem; the customer service representative tells you that they will send somebody out to look at it. For a few days, you can talk on the phone without any interruptions, but then the same problem starts again. You call the telephone company again, and the customer service representative tells you the root of this problem lies with the switching equipment in their offices that affects your line, and perhaps a few other lines as well.

After three months, during which many important phone calls are interrupted, and you repeatedly call the telephone company to complain, the problem seems to go away. You call the telephone company again to make sure that your service will not cut out again, and they tell you, that they can not guarantee anything because the problem is with the switching equipment and they really do not plan to replace that equipment any time in the future. The telephone company, however, still sends you full bills for the three months of spotty service, refuses to give any type of compensation, and does not apologize.

\section{Scenario 2: Low exit barrier and poor service recovery}

You have just moved into an area of the country where three different carriers provide local phone service. There are also several companies that offer cellular phone service as well. After finding a place to live, you gather informa- 
tion about several different providers. Based off of the information that you collected about each provider, you contact one of the local telephone companies in order to set up your phone service.

After two months of receiving good service from your local telephone provider, you begin to notice that you cannot hear people talking on the phone, although they can hear you talk. This problem is frustrating and annoying; as it requires that you hang up and call the person back in order to complete your phone conversation. You call the telephone company and tell them the problem; the customer service representative tells you that they will send somebody out to look at it. For a few days, you can talk on the phone without any interruptions, but then the same problem starts again. You call the telephone company again, and they tell you the root of this problem lies with the switching equipment in their offices that affects your line, and perhaps a few others.

After three months, during which many important phone calls are interrupted, and you repeatedly call the telephone company to complain, the problem seems to go away. You call the telephone company again to make sure that your service will not cut out again, and they tell you, that they can not guarantee anything because the problem is with the switching equipment and they really do not plan to replace that equipment any time in the future. The telephone company, however, still sends you full bills for the three months of spotty service, refuses to give any type of compensation, and does not apologize.

\section{Scenario 3: Low exit barrier and good service recovery}

You have just moved into an area of the country where three different carriers provide local phone service. There are also several companies that offer cellular phone service as well. After finding a place to live, you gather information about several different providers. Based off of the information that you collected about each provider, you contact one of the local telephone companies in order to set up your phone service.

After two months of receiving good service from your local telephone provider, you begin to notice that you cannot hear people talking on the phone, although they can hear you talk. This problem is frustrating and annoying; as it requires that you hang up and call the person back in order to complete your phone conversation. You call the telephone company and tell them the problem; the customer service representative tells you that they will send somebody out to look at it. For a few days, you can talk on the phone without any interruptions, but then the same problem starts again. You call the telephone company again, and they tell you the root of this problem lies with the switching equipment in their offices that affects your line, and perhaps a few others.

After three months, during which many important phone calls are interrupted, and you repeatedly call the telephone company to complain, the problem is finally fixed. The telephone company is very contrite and apologetic. A service representative calls you several days after the problem was fixed, as well as two weeks later, to make sure you are receiving good service. The service representative tells you that the telephone company will give you three months of free local service as compensation for the problem. In addition, the representative gives you a special telephone number to call if the problem ever occurs again, where you will receive immediate attention.

\section{Scenario 4: High exit barrier and good service recovery}

You just moved into an area of the country where the only phone service available is provided through one local telephone company. Cellular phone service is not an option available for residents of this area. So, you are limited to a single provider of local telephone service. After finding a place to live, you gather information about this particular telephone provider. Based off of the information that you collected about this provider, you contact this local telephone company in order to set up your phone service.

After two months of receiving good service from your local telephone provider, you begin to notice that you cannot hear people talking on the phone, although they can hear you talk. This problem is frustrating and annoying; as it requires that you hang up and call the person back in order to complete your phone conversation. You call the telephone company and tell them the problem; the customer service representative tells you that they will send somebody out to look at it. For a few days, you can talk on the phone without any interruptions, but then the same problem starts again. You call the telephone company again, and they tell you the root of this problem lies with the switching equipment in their offices that affects your line, and perhaps a few others.

After three months, during which many important phone calls are interrupted, and you repeatedly call the telephone company to complain, the problem is finally fixed. The telephone company is very contrite and apologetic. A service representative calls you several days after the problem was fixed, as well as two weeks later, to make sure you are receiving good service. The service representative tells you that the telephone company will give you three months of free local service as compensation for the problem. In addition, the representative gives you a special telephone number to call if the problem ever occurs again, where you will receive immediate attention. 


\section{Executive summary}

"The angry man is more foolish than the forgiving man" or "Vengeance is sweet"? Take your pick of the sayings on offer. Maybe it is far better for disgruntled customers' peace of mind, not to mention their blood pressure, to go along the "forgive-and-forget" route, but not everyone can. And, for some, disappointment, annoyance, resentment and anger can all boil over into a downright grudge.

For service providers who find themselves with grudgeholding customers (or ex-customers), the consequences can be drastic. Fortunately, most customers who harbor thoughts of vengeance tend not to turn their more extreme retaliatory fantasies into reality, but even so organizations ought to get to grips with the causes of grudges (imagined or real) and how to deal with the problem.

Although people hold grudges against a firm because of a product or service failure, for the majority it is because of the way they were treated afterwards by marketing personnel. Most people can be forgiving if something goes wrong. The problems start when they try to get it put right and come up against people - the people who should be helping, apologizing, trying to smooth things over to the customer's satisfaction - whose actions, or inaction, just make things worse.

Complaints that are not handled in a fair and speedy manner can lead to further complaint and resentment, which festers. Upset customers can desert the company (unless they are locked into a long-term arrangement or the organization is a monopoly), spend the rest of their lives bad-mouthing the company, write to newspapers or websites, start campaigns, or merely inwardly seethe and refuse to have any further contact with the company.

Matthew P. Bunker and Dwayne Ball, who believe grudgeholding needs a place in the theory of service relationships, say: "The fact that unhappy customers hold the same level of grudge whether they exit the relationship or not raises a strong possibility of a notable effect. For any service provider who has been in business long enough to have committed service failures and poor recoveries, there are former customers in his or her market area still nursing a grudge, still throwing away communications from the service provider, and still wishing that the service provider would fall down a hole."

Although they feel the place of grudge-holding in customer relationship theory is limited, they consider it important because grudge-holding predicts the desire for retaliation and the desire to avoid communication, both potentially expensive outcomes for the service provider.
Faced with the same service failures, some customers will hold a deep grudge, and some will cope in other ways. Thus, a service provider, encountering customers who do not exit, and who do not hold grudges, and who are willing to continue communication, may be fooled into thinking that this is the response of most customers to service failure.

In addition to trying to avoid service failures in the first instance, managers should put in place policies, practices, and training that allow service personnel to recognize when mere dissatisfaction will become grudge-holding, with all the attendant negative consequences. Then, when service failures do occur, managers should adopt take the "apology, compensation, response speed, and recovery initiation" steps.

Routine customer satisfaction surveys should have a grudge-holding item or two, in order to detect the level of grudge-holding, particularly since grudge-holders are less likely to initiate communication. In addition, perusal of company-focused complaint websites and searches of web logs may uncover a lot of grudge-holding.

Managers should monitor the level of apparent acts of retaliation and communication avoidance. Acts of retaliation can be vandalism, negative word-of-mouth, and passive-aggressive acts (such as paying a bill in pennies).

Communication avoidance due to grudge-holding might be detected by the ratio of dissatisfied customers to complainers. If this ratio is higher than normal benchmarks for the company or industry, it would suggest that unhappy customers are avoiding communication in greater numbers than usual, indicating grudge-holding.

Perhaps customers likely to hold grudges, but who do not communicate, can be identified by mining a customer database. For example, the company may have discovered that customers exposed to certain policies or receiving service in certain locations under certain conditions are likely to hold grudges. In this case, such customers can be approached individually and the problem corrected with sensitivity to their state of mind and appropriate apologies and compensation.

If the amount of grudge-holding is substantial, then the company may find itself with the necessity of initiating a public relations campaign to encourage still-angry customers to identify themselves and thereby receive apologies and compensation. To fail to do so would be to incur the possible consequences of large-scale grudge-holding: exodus of customers, retaliation, and communication avoidance on a large scale. 